\title{
SPATIAL DATA: FROM CARTOGRAPHY TO GEODATABASE
}

\author{
Ugo FALCHI \\ Department of Sciences and Technologies, University of Naples Parthenope, \\ Centro Direzionale - Isola C4, 80143, Naples, Italy \\ E-mail: ugo.falchi@uniparthenope.it
}

Received 5 June 2017; accepted 27 November 2017

\begin{abstract}
The final goal of this paper was to fix a brief summary on the status of geographic information in Italy due to the technological steps and national regulations. The acquisition, processing and sharing of spatial data has experienced a significant acceleration thanks to the development of computer technology and the acknowledgment of the need for standardization and homogenization of information held by public authorities and individuals. The spatial data represents the essential knowledge in the management and development of a territory both in terms of planning for safety and environmental prevention. In Italy there is an enormous heritage of spatial information which is historically affected by a problem of consistency and uniformity, in order to make it often contradictory in its use by the public decision-maker and private parties. The recent history of geographic information is characterized by a significant effort aimed at optimizing this decisive technical and cultural heritage allowing the use of it to all citizens in a logic of sharing and re-use and may finally represent a common good available to all.
\end{abstract}

Keywords: cartography, geodatabase, geotopographical database, geodesy, INSPIRE, ETRS89, Roma40.

\section{Introduction}

Directive 2007/2/EC of the European Parliament and of the Council of 14 March 2007, has set up an Infrastructure for Spatial Information in the European Community (INSPIRE); the goal is to achieve an integration of geographic information on a continental basis, through measures of coordination between the users and the providers of the information in order to combine the available knowledge in the various sectors.

The establishment of a European infrastructure as a coordinating body of the national structures, it was necessary to correct the problems regarding the availability, quality, accessibility and sharing of spatial information. To deal with these issues, it was necessary to establish new measures about sharing, access and use of spatial data and related services.

This first step paved the way for a revision of the spatial data structures, data acquisition, storage and processing techniques and sharing policies not only to reuse, stopping an unnecessary and costly proliferation of information, but most of all to let European citizens take advantage from this knowledge.

\section{Regulatory aspects}

The action in Europe was preceded in Italy by Legislative Decree 7 March 2005, n. 82, Digital Administration Code, supplemented by the Legislative Decree of April 4, 2006, n. 159, which, in Articles 59 - Spatial data and 60 - Database of national interest, laid the basis for standardization, acquisition, processing and sharing of national interest data.

These two regulatory steps are the result of an intense commitment that in Italy has been brought forward by the working groups set up within the Memorandum of Understanding, called IntesaGIS, for the activation of organic forms and methods of cooperation and coordination between Government and Local Authorities for the implementation of general interest GIS.

A lot of technical specifications and guidelines has been developed since 1995 to fix the efforts of public administration.

The "Centro Interregionale" (Interregional Center) was the local authorities coordinating board for the Italian EU Objective 1 Regions.

Since it was funded in 1980, the "Centro Interregionale", Center for Coordination and Documentation 
of Territorial Information, voluntary association among the Regions and Autonomous Provinces, operates in the field of spatial information to support the regions and autonomous provinces for the coordination of initiatives, the spread of information and cultural updating, was the link with the central structures of the state.

From 30 November 2007, it joined CISIS - Interregional Center for Geographic and Statistic Information Systems; the new statute approved by CISIS, alongside the existing Standing Committees for Information Systems and Statistics, was established the Permanent Committee for Geographic Information Systems (CPSG).

At ministerial level, it has been followed by different entities such as AIPA, Authority for Information Technology in Public Administration, established by Legislative Decree No. 39 of 12 February 1993, it merged into the CNIPA, National Centre for Computing in Public administration, established by article 176 of Legislative Decree No 30 June 2003, 196 and later turned into DigitPA, created under the Decree 1 December 2009, n. 177 "Reorganization of the National Centre for Computing in Public Administration, in accordance with Article 24 of Law 18 June 2009, n. 69.

So far the last step is the Agency for Italy Digital AGID; this institution was established by Decree 83, converted into Law no. 134/2012.

It inherits the skills of the Department for Digitization and Innovation, of DigitPA and of the Institute for communications and information technology.

All the experience represented by different technical committees and all the material produced, has merged into the Committee for the technical rules on the spatial data by public authorities, established under Article 59 of the CAD.

We have arrived at the present time and, despite the many difficulties in the activation of this Committee and the identification of the Director, the different working groups have laboriously started to spin the web of the new specifications necessitated by Decree 10 November 2011 (Official Gazette no. 48 of 27/02/2012 - Ordinary Supplement n. 37).

This decree, in addition to the adoption of a new National Geodetic Reference System, established new technical rules for defining the specific content of the geographical database and new technical rules for the definition of the content of the National Directory of spatial data, as well as the first constitution and updating of the database.

This is a real revolution; the old system of GaussBoaga and its Datum Roma40 was forced out and was imposed, as a national geodetic reference system, the realization ETRF2000 (2008.0) of the European Geodetic Reference System ETRS89.

It was obtained by Military Geographical Institute in 2009, through the identification of permanent stations, the acquisition of data and the calculation of the Dynamics National Network (RDN) and was also resurrected the National Directory of spatial data already set up at DigitPA (former CNIPA), in accordance with Article 59, paragraph 3, of Legislative Decree 7 March 2005 n. 82.

The Directory is the national catalog of metadata on spatial data and relative services; it is held by public authorities and by the entities that apply for their integration.

On May 13th, 2014, in the presence of CISIS, Italian IRS, Ispra, IGM, IIM, The Lombardy regional administration and AGEA, the state of arte was evaluated of the different actions of the parties involved and the stage set up for a new activation of working groups and the tasks assigned to them.

The working groups are:

1. GdL1 - Working Group on metadata and RNDT (coordinated by AGID);

2. GdL2 - Working Group on geotopographical DB (coordinated by CISIS);

3. GdL3 - Working Group on GNSS network (coordinated by IGM);

4. GdL4 - Working Group on orthophotos 1:5000, DTM and remote sensing (coordinated by AGEA);

5. GdL5 - Working Group on the implementation of the INSPIRE Directive (coordinated by ISPRA);

6. GdL6 - Working Group on open data geography (coordinated by AGID);

7. GdL7 - Working Group on the sea information (coordinated by the IIM);

8. GdL8 - Working Group on sub-service networks (coordinated by the Regional Administration of Lombardy).

\section{National Geodetic System}

The EUREF, Regional Reference Frame Sub-Commission for Europe, is a sub-committee of the International Association of Geodesy, IAG; it is part of the sub commission 1.3 (Regional Reference Frames) which was placed under the IAG Commission 1 (Reference Frames).

This association has the task of defining, achieving and the maintenance of the realization of the European geodetic reference (European Geodetic Reference 
Frame) and with establishment of a continental unique geodetic datum (ETRS89) and a network of reference stations (EPN) through the EU territory.

Established in Vancouver in 1987, during the General Assembly of IUGG (International Union of Geodesy and Geophysics), the EUREF adopted in Florence in 1990 the following resolution no. 1: recognizing the availability of the International Terrestrial Reference System (ITRS) which has been established by the International Earth Rotation Service (IERS) which is accepted worldwide and which uses SLR, LLR and VLBI observations and noting that in such a system station positions in Europe have a common motion of the order of one centimeter per year recommends that the system to be adopted by EUREF will be coincident with ITRS at the Epoch 1989.0 and fixed to the stable part of the Eurasian Plate and will be known as European Terrestrial Reference System 89 (ETRS 89) and accepts that this geocentric system will coincide with the World Geodetic System 84 (WGS 84) at the one metre level and that, for most applications, the coordinates will have no time variation.

ETRS has already been adopted by most of the European nations. In Italy, the materialization of the standard ETRS were, first, the network IGM95 and, currently, the National Dynamic Network (RDN). Both geodetic networks have been established and are managed by the Istituto Geografico Militare Italiano, IGMI (Italian Military Geographic Institute).

Thanks to the Ministerial Italian Decree November 10, 2011, Adoption of the National Geodetic Reference System, Italy has accepted the recommendations of the Commission EUREF; Art. 2 - National Geodetic Reference System, it says: “...the National Geodetic Reference System adopted by the Italian government, is the ETRF2000 - epoch 2008.0 - of European Geodetic Reference System ETRS89, obtained in 2009 from Istituto Geografico Militare, through the identification of permanent stations, the acquisition of data and the calculation of the National Dynamic Network"

The subsequent articles of the Decree impose the adoption of this system and shall state the transformation of the existing geographical information as well as expressed in the SIFET scientific journal article, The new national geodetic reference system: current status and future prospects (Maseroli 2013: 67-83).

\section{Geotopographical database}

New technologies and the need to support greater accuracies achieved have pushed the entire industry towards a phase of innovation.
It's a long way from the first aerophotogrammetric analog printed maps to the use of the digital, used both the process of acquisition and restitution and the treatment, storage, querying and sharing of spatial data.

If it's only been a few decades, we have gone from paper, precious and unique result of the work of weeks and often months, through GIS to geographical information stored into geotopographical databases, DBGT, as defined in Annexes 1 and 2, November 10, Italian Ministerial Decree 2011, Italian Decree November 10, 2011. Technical rules for the definition of the content of the National Directory of spatial data, and the ways in first constitution and updating and Italian Decree November 10, 2011. Technical rules for defining the specific content of the database geotopografici, Attachments 1 and 2.

The architecture of the first databases evolved into more complex configurations and better conceptual modeling approach to support an update database design for a multi-representation of the real world phenomena interoperable at European level.

In the spatial data catalog, contained in Annex 1 of the above Decree, it was confirmed the setting of previous published specifications and relates with developing and integrating some aspects of the content; inter alia:

- the same organization has been kept regarding object definition for layers, themes and classes;

- each class is characterized by its own description: thematic attributes and their domains, spatial and temporal features and their attributes;

- for each class are specified relations and constraints on the spatial features;

- selected the contents of the "National Core" (minimum content that must be present in databases) at scale 1: 1000/2000 and 1:5000/10 000 in terms of classes and their attributes, domains and spatial features.

The model GeoUML (Geographic Unified Modeling Language) is used for the definition of the conceptual model.

The composition of this pattern consists of a set of elements distributed in two categories:

- the information elements useful for establishing the contents consist of: class, attribute (nongeometric), cardinality, enumerated domain, hierarchical domains, association, inheritance, space features and their attribute, primary key, topological layer; 
- integrity constraints, define the properties that the data must satisfy and are composed of two types of spatial integrity constraints: the topological constraints and the composition constraints.

In support of geotopographical databases design, according to the characteristics required by national regulations, the SpatialDBgroup, a group of researchers from the Department DEIB, Politecnico di Milano, and the Department of Computer Science, University of Verona, supported by CISIS, have developed two series of tools:

- the GeoUML Tools, developed from 2008 to 2011 on behalf of CISIS (Interregional Center for computer systems, geographical and statistical), which are currently used by several Italian institutions for the design and validation of their geotopographical databases;

- the INSPIRE Data Model (IDM) Tools, a project started in 2013 to apply the GeoUML experience to design a INSPIRE database for server WFS; they produced the first version in June 2014.

These tools represent the cutting edge application for the structuring of a database, and the verification of compliance with downstream production.

Another front of open development, although not explicitly included in the intention of the Decree, is the use of an original conceptual model, capable of expressing the different representations (scale, time) of the same geographic entities and relationships between them, directly into the geodatabase structure, by inserting an additional level of abstraction (Falchi 2016).

In actual models it is hard to introduce additional information within the same scheme, such as the relationship between time and spatial features or a multi representation vision.

These objectives have been the subject of several important Italian and European projects and research of the Department of Science and Technology of the University of Naples "Parthenope".

\section{Innovation}

The profound changes that have occurred in recent years have been generated by a new deal in the acquisition of spatial data both in its treatment and management.

The technological evolution and architectural structures used has interested the entire chain of geomatics and pushed for the adoption of methodologies and systems that are better adapted to reproduce the accuracy of data achieved.
If whilst the adoption of the new national geodetic system is justified by the need to fully support the increased precision obtained by the RTK methodology, now widely available and not supported by the IGM95 network, the modeling of the data within geotopographical database was the natural result of the need for greater usability and standardization of geographic information.

From aerophotogrammetric survey run with digital multispectral technology GPS / INS camera for direct geo referencing or with the use of photogrammetric satellites, to the photogrammetric multi digital oblique camera to realize Digital Surface Model, DSM (Pepe, Prezioso 2016), to the RTK land survey performed with GNSS equipment, to the multi-resolution and multi representation databases until to the evolution of national and international geodetic systems, all the disciplines involved in the creation and processing of spatial data have provided a contribution to offer to the end user increasing precision and better representation of geographic information.

\section{Conclusions}

Italian and European relevant work of dissemination showed that the geographic information represents a common good rather than a property, a service rather than a product.

The need for re-use and sharing of this information together with a greater accuracy of results requested and obtained from the academic community and professional, have opened the way for both a renewal of process techniques used.

Such progress has been interpreted in Europe with the overcoming of national barriers, directed to a homogenization and optimization of the immense territorial information of the Member States of the European Community.

Matter still in progress, this site is always open to seize the opportunities that the technological and scientific progress is able to offer.

Italian universities and scientific groups dealing with these disciplines are the best workshops for innovation in the study and validation of systems and techniques of tomorrow.

\section{Acknowledgements}

This research was part of the "New Geodetic Reference System and GNSS data quality" project supported by the University of Naples "Parthenope". In loving memory of Prof. Raffaele Santamaria, the former Director 
of the Department of Sciences and Technologies, University of Naples "Parthenope", for his fatherly help and scientific support of our research activities.

\section{Disclosure statement}

Authors do not have any competing financial, professional or personal interests from other parties.

\section{References}

Directive 2007/2/EC of the European Parliament and of the Council, 14 March 2007.

Falchi, U. 2016. A conceptual model for the management of multi-representation geographical information, International Journal of Engineering and Technology 7(6): 2061-2068.

Italian Decree November 10, 2011. Adoption of the National Geodetic Reference System.

Italian Decree November 10, 2011. Technical rules for the definition of the content of the National Directory of spatial data, and the ways in first constitution and updating.

Italian Decree November 10, 2011. Technical rules for defining the specific content of the database geotopografici. Attachments 1 and 2 .
Maseroli, R. 2013. The new national geodetic reference system: current status and future prospects, SIFET Bulletin 1(2013): 67-83.

Official Gazette no. 48 of 27/02/2012 - Ordinary Supplement n. 37.

Pepe, M.; Prezioso, G. 2016. Two approaches for dense DSM generation from aerial digital oblique camera system, in Proceedings of the 2nd International Conference on Geographical Information Systems Theory, Applications and Management, Vol. 1: GISTAM. ISBN 978-989-758-188-5.

https://doi.org/10.5220/0005774900630070

Ugo FALCHI. He is tenured Assistant Professor at the Department of Sciences and Technologies, University of Naples "Parthenope" for Scientific and Disciplinary Group ICAR/06 - Topography and Cartography. Graduated with full marks in Civil Engineering at University of Cagliari, he obtained his Research Fellowship at University of Cagliari with a research titled: "The automatic cartographic generalization in GIS enviroment". He has participated to research projects financed by MIUR, UE, taking care himself of Geographical database, Cartography, GIS and Photogrammetry. He is a PhD Doctoral College Professor and Tutor in Geomatica, Navigation and Geodesy. He is author or co-author of more than 20 papers published in scientific journals or proceedings of National or International Conferences. 